\title{
Numerous microRNPs in neuronal cells containing novel microRNAs
}

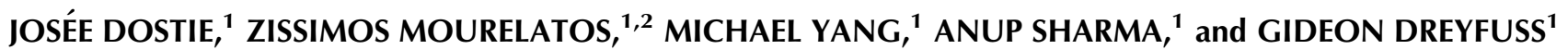 \\ ${ }^{1}$ Howard Hughes Medical Institute, and Department of Biochemistry and Biophysics, University of Pennsylvania School of Medicine, \\ Philadelphia, Pennsylvania 19104-6148, USA \\ ${ }^{2}$ Department of Pathology, University of Pennsylvania School of Medicine, Philadelphia, Pennsylvania 19104-6148, USA
}

\begin{abstract}
Spinal muscular atrophy (SMA) is a common neurodegenerative disease that is caused by deletions or loss-of-function mutations in the Survival of Motor Neuron (SMN) protein. SMN is part of a large complex that functions in the assembly/restructuring of ribonucleoprotein (RNP) complexes. We recently showed in HeLa cells that two components of the SMN complex, Gemin3 and Gemin4, together with the argonaute protein eIF2C2, also associate with microRNAs (miRNAs) as part of a novel class of RNPs termed miRNPs. Here we report on miRNPs isolated from neuronal cell lines of mouse and human, and describe 53 novel miRNAs. Several of these miRNAs are conserved in divergent organisms, including rat, zebrafish, pufferfish, and the nematode Caenorhabditis elegans. The chromosomal locations of most of the novel miRNAs were identified and indicate some phylogenetic conservation of the likely precursor structures. Interestingly the gene locus of one miRNA, miR-175, is a candidate region for two neurologic diseases: early-onset parkinsonism (Waisman syndrome) and X-linked mental retardation (MRX3). Also, several miRNAs identified as part of miRNPs in these cells appear to constitute two distinct subfamilies. These subfamilies comprise multiple copies of miRNAs on different chromosomes, suggesting an important function in the regulation of gene expression.
\end{abstract}

Keywords: Gemin3; miRNAs; SMA; motor neurons

\section{INTRODUCTION}

MicroRNAs (miRNAs) are a large family of short (20-24nt) single-stranded noncoding regulatory RNAs that includes the small temporal RNAs (stRNAs) lin-4 and let-7 (Ambros and Horvitz 1984; Reinhart et al. 2000). Based on knowledge gained from studies on stRNAs, miRNAs are thought to modulate gene expression by partially base-pairing with target mRNA sequences. Members of this new class of RNAs have been found in several metazoans including Caenorhabditis elegans (Lau et al. 2001; Lee and Ambros 2001), mouse (Lagos-Quintana et al. 2002), and humans (Lagos-Quintana et al. 2001; Mourelatos et al. 2002). miRNAs appear to be derived from the processing of larger precursors of approximately $70 \mathrm{nt}$ or longer. The precursors are predicted to form imperfect stem-loop structures from

Reprint requests to: Gideon Dreyfuss, Howard Hughes Medical Institute and Department of Biochemistry and Biophysics, University of Pennsylvania School of Medicine, Philadelphia, PA 19104-6148, USA; e-mail: gdreyfuss@hhmi.upenn.edu; fax: (215) 573-2000.

Article and publication are at http://www.rnajournal.org/cgi/doi/ 10.1261/rna.2141503. which the mature miRNAs are excised from one half of the stem by a process that involves the RNAse III enzyme Dicer (Hutvagner et al. 2001).

miRNAs were recently shown to be components of a novel class of ribonucleoprotein (RNP) complexes termed miRNPs (Mourelatos et al. 2002). These complexes sediment as $15 \mathrm{~S}$ particles in sucrose gradients and were found to contain the proteins Gemin3 (a DEAD-box putative RNA helicase; Charroux et al. 1999), Gemin4 (Charroux et al. 2000), and eIF2C2, a member of the argonaute family of proteins (Mourelatos et al. 2002). Gemin3 and Gemin4 are also components of the SMN complex, a large multiprotein complex containing the Survival of Motor Neuron (SMN) protein, Gemin2 (formerly SIP 1; Liu et al. 1997), Gemin5 (Meister et al. 2001; Gubitz et al. 2002), Gemin6 (Paushkin et al. 2002; Pellizzoni et al. 2002), and Gemin7 (Baccon et al. 2002). The SMN complex functions in the assembly/ restructuring of RNPs, including spliceosomal small nuclear RNPs (snRNPs; Fischer et al. 1997; Pellizzoni et al. 1998; Meister et al. 2001), and possibly small nucleolar RNPs (snoRNPs; Jones et al. 2001; Pellizzoni et al. 2001a), heterogeneous nuclear RNPs (hnRNPs; Mourelatos et al. 2001), and transcriptosomes (Pellizzoni et al. 2001b). 
Deletion or loss-of-function mutations in SMN cause spinal muscular atrophy (SMA), a common genetic disease characterized by progressive degeneration of motor neurons (Melki 1997). Because Gemin3 and Gemin4 are shared components of the SMN and miRNP complexes, deletion or loss-of-function mutations of SMN in SMA may also affect the activity of miRNPs due to possible redistribution or changes in the levels of Gemin3 and Gemin4. Thus, it is possible that specific or general changes in the activity of the miRNPs play a role in the development of SMA. However, it was not known whether Gemin3 also associates with miRNAs in motor neuron cells, which are specifically affected in SMA. Furthermore, miRNAs associated with miRNPs in this cell type have not been previously identified. Here we report on the characterization of miRNAs associated with miRNPs isolated from neuronal cells. We identified 53 novel miRNAs from mouse and human neuronal cell lines, several of which are phylogenetically conserved in divergent organisms. The predicted precursor structure of most of these miRNAs was determined from known genomic sequences. Several miRNAs were found to constitute distinct subfamilies comprising multiple copies on different chromosomes, suggesting that these miRNAs play an important role in the regulation of gene expression.

\section{RESULTS AND DISCUSSION}

\section{Gemin3 associates with miRNAs in neuronal cell lines}

Because SMA specifically affects motor neurons, we wished to study miRNPs in well characterized neuronal cell lines. To do so, total extracts from mouse motor neuron MN-1 cells (Salazar-Grueso et al. 1991; Brooks et al. 1997) and human retinoblastoma Weri cells (McFall et al. 1977) were incubated with either the anti-Gemin3 antibody (11G9) or with the nonimmune mouse serum (NMS) as control. The immunoprecipitates were digested with proteinase $\mathrm{K}$, and the associated RNAs were isolated. The extracted RNAs were $3^{\prime}$-end-labeled with $\left[5^{\prime}{ }^{32} \mathrm{P}\right]$-pCp, resolved by gel electrophoresis, and visualized by autoradiography. As shown in Figure 1, short ( 24-nt) RNAs were specifically coimmunoprecipitated with the anti-Gemin3 antibody but not with the control antibody in both $\mathrm{MN}-1$ and Weri cells. This indicates that Gemin3 is associated with small RNAs not only in HeLa cells (Mourelatos et al. 2002), and suggests that Gemin3 interacts with miRNAs in various cell types including motor neuron cells, as part of miRNPs.

\section{Identification and characterization of miRNAs}

To identify the miRNAs in these cells, the RNAs were cloned as previously described (Elbashir et al. 2001; Mourelatos et al. 2002). A total of 107 clones from Weri and MN-1

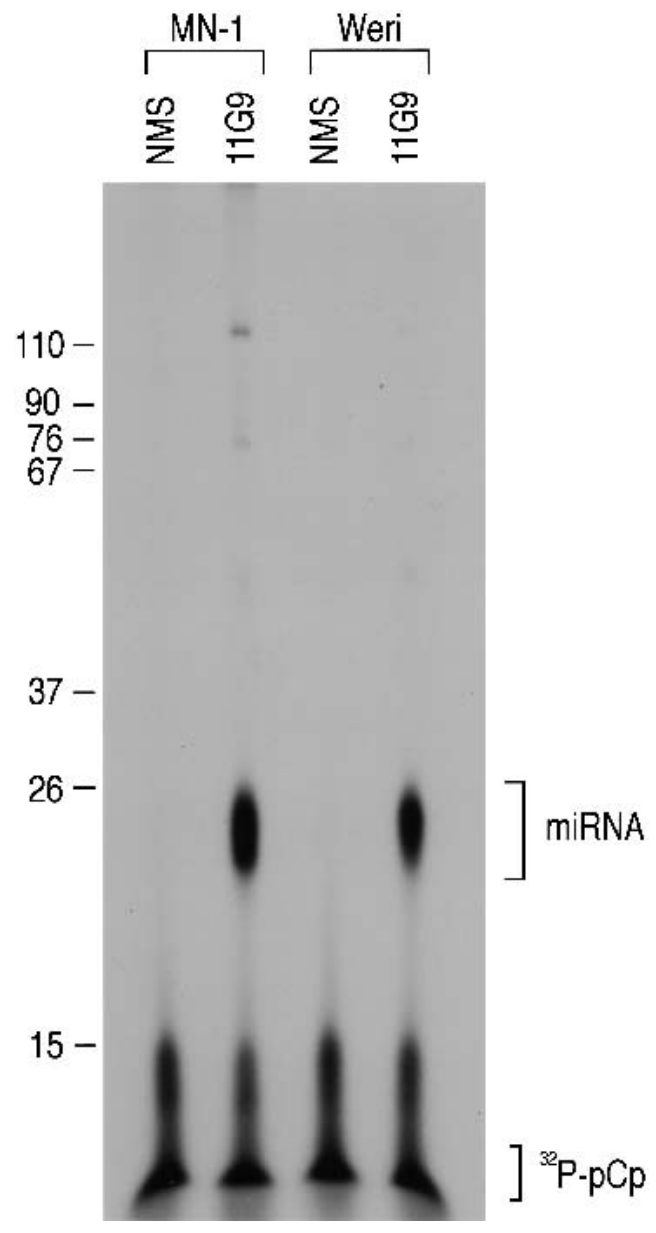

FIGURE 1. miRNPs from mouse and human neuronal cells. Total extracts from MN-1 (mouse) and Weri (human) cells were incubated with either nonimmune mouse serum (NMS) as a control or the anti-Gemin3 antibody (11G9). Immunoprecipitates were treated with proteinase $\mathrm{K}$, and associated RNAs were purified by phenol-chloroform extraction and precipitated. Isolated RNAs were $3^{\prime}$-end-labeled with $\left[5^{\prime}-{ }^{32} \mathrm{P}\right]-\mathrm{pCp}$ and resolved by electrophoresis on $15 \%$ denaturing polyacrylamide gels. Left: molecular weight marker.

cells were sequenced. We found 41 different miRNAs associated with miRNPs in Weri cells, six of which were also found with miRNPs in HeLa cells (Table 1, miRNAs in bold letters; Mourelatos et al. 2002). Several miRNAs previously identified from total RNA, including let-7, miR-15, miR-20, miR-21, miR-29a, and the more recently described miR15b, miR-27b, miR-29c, and neuronal-specific miR-124a (Lagos-Quintana et al. 2002) were also found, indicating that miRNPs also play a role in the metabolism of these miRNAs. Interestingly, 25 novel miRNAs were found in the miRNP from human neuronal cells, and three additional miRNAs were identified by sequence homology to the new miRNAs identified in the present study. Most miRNAs can be localized in the human genome, and are highly conserved in other organisms with little sequence variation. The precursor sequence and secondary structure of miRNAs that are found on several chromosomes in one species and/ 
TABLE 1. miRNA sequences associated with miRNPs in the Weri human neuronal cell line

\begin{tabular}{|c|c|c|c|c|c|c|c|c|c|c|c|}
\hline \multirow[b]{2}{*}{ miRNA } & \multirow[b]{2}{*}{$\begin{array}{l}\text { Number of } \\
\text { clones }\end{array}$} & \multirow[b]{2}{*}{ miRNA sequence } & \multirow[b]{2}{*}{$\begin{array}{l}\text { Size } \\
(\mathrm{nt})\end{array}$} & \multirow[b]{2}{*}{ Source } & \multicolumn{7}{|c|}{ Predicted Precursors } \\
\hline & & & & & Hs (Chr.) & Dr & Fr & $\mathrm{Dm}$ & $\mathrm{Ce}$ & $\mathrm{Mm}$ & $\mathrm{Rn}$ \\
\hline let-7a & 1 & UGAGGUAGUAGGUUGUAUAGUU & 22 & $\mathrm{Hs}$ & $+(9,11,22)$ & - & + & + & + & + & + \\
\hline miR-15a & 1 & UAGCAGCACAUAAUGGUUUGUGA & 23 & Hs & $+\quad(13)$ & + & + & - & - & - & - \\
\hline miR-15b & 1 & UAGCAGCACAUCAUGGUUUAC & 21 & $\mathrm{H} \mathrm{s}, \mathrm{Mm}$ & $+(3)$ & - & - & - & - & + & - \\
\hline miR-19a & 4 & UGUGCAAAUCUAUGCAAAACUGA & 23 & Hs & $+(13)$ & - & + & - & + & - & + \\
\hline miR-19b & 4 & UGUGCAAAUCCAUGCAAAACUGA & 23 & $\mathrm{Hs}$ & $+(13, X)$ & - & + & - & - & - & + \\
\hline miR-20 & 8 & UAAAGUGCUUAUAGUGCAGGUAG & 23 & $\mathrm{Hs}$ & $+(13)$ & - & + & - & - & - & + \\
\hline $\operatorname{miR}-21$ & 1 & AGUUAGCUJUAUCAGACUGAUGUUGA & 25 & $\mathrm{Hs}$ & $+(13)$ & - & + & - & - & - & + \\
\hline $\operatorname{miR}-27 b$ & 1 & GUUCACAGUGGCUAAGUUCUG & 21 & IIs, Mm & & - & + & - & - & + & + \\
\hline miR-29a & 1 & UAGCACCAUICUGAAAUCGGUUA & 22 & Hs & $+(7.1,7.2)$ & - & - & - & - & + & + \\
\hline $\operatorname{miR}-29 \mathrm{c}$ & 1 & UAGCACCAUUUGAAAUCGGUUA & 22 & Hs & + (1) & - & + & - & - & - & + \\
\hline miR-91 & 5 & CAMAGUGCUUACAGUGCAGGUAG & 23 & $\mathrm{Hs}$ & + (13) & - & + & - & - & - & + \\
\hline miR-92 & 3 & UAUUGCACUUGUCCOGGCCUGU & 22 & Hs & $+(13, X)$ & - & + & + & - & - & + \\
\hline miR-93 & 1 & AAAGUGCUGUUCGUGCAGGUAG & 22 & Hs & $+(7.1,7.2)$ & - & + & - & - & + & - \\
\hline miR-94 & 1 & UAAAGUGCUGACAGUGC $A G A U A$ & 22 & Hs & $+(7.1,7.2)$ & - & - & - & - & + & - \\
\hline $\operatorname{miR}-106$ & 1 & AAAAGUGCUUACAGUGCAGGUAGC & 24 & Hs & $+(\mathrm{X})$ & - & + & - & - & - & - \\
\hline $\operatorname{miR}-124 a$ & 3 & UAAGGCACGCGGUGAAUGCCAA & 22 & Hs & $+(8.1,8,2,20)$ & - & + & + & + & - & - \\
\hline $\operatorname{miR}-172$ & 2 & UGGCAGUGUCUUAGCUGGUUGUU & 23 & $\mathrm{Hs}$ & $+(1)$ & - & + & - & - & + & - \\
\hline $\operatorname{miR}-173$ & 1 & CACGGGGAGGUAGUGACGAAA & 21 & Hs & $+(2.1,2.2)$ & - & - & + & - & . & + \\
\hline $\operatorname{miR}-174$ & 1 & UAUOGCACUGGUAGAAUUCACU & 22 & IIs & $+(7)$ & + & + & + & - & - & - \\
\hline miR-175 & 1 & CAAGUCACUAGUGGUUCCGUUUAA & 23 & Hs & (X) & - & - & + & - & + & - \\
\hline miR-176 & 1 & GGACUGCCUCAGCUGUGC & 18 & Hs & (2) & - & . & - & - & - & - \\
\hline $\operatorname{miR}-177$ & 1 & GUGUCCUAAGGUGAGCUCAG & 20 & Hs & $-(8)$ & - & - & - & + & + & + \\
\hline $\operatorname{miR}-178$ & I & AACAUUCAACGCUGUCGGUGAGUU & 25 & $\mathrm{Hs}, \mathrm{Mm}$ & $+(1,9)$ & - & + & - & - & + & + \\
\hline $\operatorname{miR}-179$ & 1 & GGUUGAUAGGUCGGGGGUGUAA & 22 & $\mathrm{Hs}, \mathrm{Mm}$ & - & - & - & - & - & - & - \\
\hline $\operatorname{miR}-180$ & 1 & АUUUC $\triangle$ GGUGAAGUIJCAAGAGUC & 24 & $\mathrm{Hs}, \mathrm{Mm}$ & - & - & - & . & - & - & - \\
\hline miR-181 & 1 & GUGCUAGGGALUGGGGCUUG & 20 & $\mathrm{Hs}, \mathrm{Mm}$ & - & - & - & - & . & + & + \\
\hline miR-182a & 1 & CAAAGUGCUGUUAGUGCAGGUAG & 23 & $\mathrm{Hs}$ & - & - & + & - & - & - & + \\
\hline $\operatorname{miR}-182 \mathrm{~b}$ & - & CAAAGUGCUGUUUAUUGCAGG & 20 & - & (11) & - & - & - & - & - & + \\
\hline $\operatorname{miR}-183$ & 2 & ACUACG $A$ AUGAUAACAUCCGUGG & 23 & $\mathrm{Hs}$ & - & - & - & - & - & - & . \\
\hline mik-184 & 1 & AUGCAAGUCGAGCUUGAAGUЛUC & 23 & Hs & - & - & - & - & . & - & - \\
\hline miR-185 & 1 & AUCGUUAUUAUCGAUGGCGUGA & 22 & $\mathrm{Hs}$ & - & - & - & - & - & - & - \\
\hline $\operatorname{miR}=186$ & 1 & CGGCCUUAGUCGUCGGGGUGAUU & 2.3 & $\mathrm{Hs}$ & - & - & - & - & - & - & - \\
\hline IniR-187 & 1 & AGGAGCACAGCUGGGUAUCUAAGU & 24 & Hs & - & - & - & - & - & - & - \\
\hline $\operatorname{miR}-188$ & 1 & CAACCUUGGGAUACC $\triangle C C C U G U A$ & 23 & $\mathrm{Hs}$ & - & - & - & - & - & - & - \\
\hline miR-189 & 1 & CGUAGACCCGAAACCGGGUGAC & 22 & $\mathrm{Hs}$ & - & - & - & - & - & - & - \\
\hline $\operatorname{mik}-190$ & 1 & UACCGCAUAAUGUUGAAAGAUGG & 23 & $\mathrm{Hs}$ & - & - & - & - & - & - & - \\
\hline miR-19l & 1 & CGGUUCAUACCCGAAGGGUCGCAA & 24 & Hs & - & - & - & - & - & - & - \\
\hline $\mathrm{miR}-192$ & 1 & AUAACGUUGAAAGAUGGCAUC & 21 & Hs & - & - & - & - & - & - & - \\
\hline miR-193 & 1 & CGAGCCGUCGUUAGACCACGACGUU & 24 & $\mathrm{Hs}$ & - & - & - & - & - & - & - \\
\hline miR-194 & 1 & GCCGUCGUCGACGAGUGCACUU & 22 & Hs & - & - & - & - & - & - & - \\
\hline $\operatorname{miR}-195$ & 1 & CAAAGUGCULACAGUUCAGGUAG & 23 & Hs & - & - & - & - & - & - & - \\
\hline miR-196a & 1 & UAAGGGCUGGGCOGGUCGGGCU & 22 & $\mathrm{Hs}, \mathrm{Mm}$ & - & - & - & - & - & - & - \\
\hline $\operatorname{miR}-196 \mathrm{~b}$ & - & UAAGGGCUGGGUCGGUCGGGCU & 22 & - & (13) & - & - & - & - & - & + \\
\hline mik-196 & - & GGGCUGGGCCGGUCGGGC & 18 & - & (10) & - & - & - & - & - & - \\
\hline
\end{tabular}

The short (22-25 nt) RNAs associated with miRNPs in Weri cells were cloned as previously described (Elbashir et al. 2001), and a total of 64 clones were sequenced. miRNAs in bold letters were previously shown to associate with miRNPs in HeLa cells. The miRNA sequences are shown $5^{\prime}$ to $3^{\prime}$. The source (Hs; Homo sapiens, Mm; Mus musculus) indicates the species of the cell line from which the miRNAs were identified. In this column, - indicates miRNAs identified by sequence homology in the human genome. (Chr.); chromosomal localization of the miRNA in the human genome. Dr; Danio rerio, Fr; Fugu rubripes, Dm; Drosophila melanogaster, Ce; Caenorhabditis elegans, Mm; Mus musculus, Rn; Rattus norvegicus. + indicates fully conserved miRNAs, and + in red color represents conserved miRNAs containing one or two mismatches.

or in several species are often moderately conserved (data not shown). Seven miRNAs were identified in both Weri and MN-1 miRNPs (Table 1). Of these RNAs, three could not be mapped in either the human or mouse genome, and one, miRNA-181, is found in the mouse and rat genomes but not in the available sequences of the human genome. The miRNAs that have no database entry do not correspond to any known structural or messenger RNAs, and thus are most likely present in repetitive genomic regions or in genomic domains that are not yet fully sequenced.

Including the miRNAs found in both cell lines (Table 1), 40 different miRNAs were found associated with miRNPs in MN-1 cells (Table 2; Mourelatos et al. 2002). These include
10 miRNAs previously shown to be in miRNPs in HeLa cells (miRNAs in bold letters), and miR-23b and miR-26b that were recently described from total mouse RNA (LagosQuintana et al. 2002). We found 23 new miRNAs in the miRNPs from mouse neuronal cells, and identified two additional miRNAs by sequence homology in the human genome. Similarly to human miRNAs, most mouse sequences are conserved and can be localized by database search in the genome of at least one organism. The miRNAs that have not been localized in the human genome are either not present, not sufficiently conserved in human to be identified, or present in genomic regions that are not yet fully sequenced. Although several of the miRNAs were analyzed 
TABLE 2. miRNA sequences associated with miRNPs in the MN-1 mouse neuronal cell line

\begin{tabular}{|c|c|c|c|c|c|c|c|c|c|c|c|}
\hline \multirow[b]{2}{*}{ miRNA } & \multirow[b]{2}{*}{$\begin{array}{l}\text { Number of } \\
\text { clones }\end{array}$} & \multirow[b]{2}{*}{ miRNA sequence } & \multirow[b]{2}{*}{$\begin{array}{l}\text { Size } \\
\text { (nt) }\end{array}$} & \multirow[b]{2}{*}{ Source } & \multicolumn{7}{|c|}{ Predicted Precursors } \\
\hline & & & & & Ifs (Chr.) & $\mathrm{Dr}$ & $F_{T}$ & Dm & $\mathrm{Ce}$ & Min & Rn \\
\hline miR-16 & 1 & UAGCAGCACGUAAAUAITJGGCG & 22 & $\mathrm{Mm}$ & $+\{3,13)$ & . & + & - & - & + & - \\
\hline miR-1\%a & 1 & UGUGCAAAUCUAUGCAMACUGA & 23 & $\mathrm{Mm}$ & $+\quad$ (13) & - & + & . & + & - & + \\
\hline miR-1\% & 2 & UGUGCAAAUCCAUGCAAAACUCIA & 23 & $\mathrm{Mm}$ & $+(13, X)$ & - & + & - & - & . & + \\
\hline mIR-2I & 1 & UAGCUUAUCAGACUGALKGUUGAC: & 22 & Min & $+\quad(\mathrm{I} 3)$ & - & + & . & . & - & + \\
\hline miR-22 & 1 & AAGCUGOCAGUUGAAGAACUG & 21 & Mnn & $+\quad(17)$ & - & - & - & . & + & + \\
\hline$m i R-23 b$ & 2 & AUCACAUUGCCAGGGAUUACCAC & 23 & $\mathrm{Mm}$ & $+(9)$ & - & + & - & - & - & - \\
\hline miR-24 & 2 & WGGCUCAGUU CAGCAGGAACAGA & 23 & $\mathrm{Mm}$ & $+(9,19)$ & - & + & - & - & + & + \\
\hline$m i R-26 b$ & $\mathrm{t}$ & UIJCAAGI IAAI I TCAGGAIJAGGUЛU J & 2.7 & $\mathrm{Mm}$ & $+\quad(2)$ & - & + & - & - & + & + \\
\hline mik-27 & 2 & UUCACAGUGGCUAAGUUCCGC & 21 & $\mathrm{Mnn}$ & $+\quad(19)$ & . & + & - & - & + & - \\
\hline$m(R-103$ & i & AGCAGCAUUGUACAGGGCUAUGA & 23 & $\mathrm{Mn}$ & $+(5,10,20)$ & . & + & - & - & + & + \\
\hline mik-197 & 1 & CAAAGAAUUCUCCUUULGGGCUU & 23 & $\mathrm{Mm}$ & $+\quad(1)$ & . & . & - & - & . & - \\
\hline$m i R=198$ & $i$ & ACUGGACUUGGAGUCAAAAGG & 21 & $\mathrm{Mm}$ & (4) & - & - & - & - & . & - \\
\hline miR-199a & $i$ & UGAUUCGGUGGGUGGUTGGUGC & 21 & $\mathrm{Mm}$ & . & . & - & - & - & - & - \\
\hline miR-199b & - & UGAUUCCGUGGGUGGUGGUGC & 21 & - & $+(19)$ & . & - & - & - & - & + \\
\hline miR-199c & - & UGAUUCUGUGGGUGGUGGUGC & 21 & - & $+(11,17)$ & - & - & - & - & + & + \\
\hline miR-200 & 1 & UGUANACAUCCCCGACUGGAA & 22 & Mm & $+\quad(8)$ & - & + & - & - & + & - \\
\hline miR-20l & $i$ & ССUGGGAUGCC:AAGIЛUЛUGAC: & 20 & $\mathrm{Mrn}$ & (4) & - & - & - & - & - & - \\
\hline $\mathrm{miR}-202$ & 1 & CAGUGCAAUGLUIAAAAGGGCAU & 22 & Mm & (ii) & . & + & - & - & - & + \\
\hline $\mathrm{miR}-203$ & 1 & $\begin{array}{l}\text { GUGCUAGGAUUGGGGCU } \\
\text { GuG }\end{array}$ & 17 & $\mathrm{Mm}$ & $+\quad 43$ & - & . & . & - & - & + \\
\hline miR-204 & 1 & ACAGUAGUIUUCACAUUGGUUA & 22 & Min & $+(I, 9.19)$ & . & - & . & - & + & + \\
\hline miR-205 & 1 & AGCCAAUGGUGCOAAGCUA & 19 & $\mathrm{Mm}$ & $+(8,11,17)$ & . & - & . & - & + & . \\
\hline miR-206 & 1 & UGUUGAAAAAGCAUGGGAUG & 20 & Mm & $+\quad(13\rangle)$ & - & - & - & - & + & + \\
\hline miR-207 & i & UAAAGIGCUGACAGCUCAGAUA & 22 & Mm & - & - & - & - & - & - & - \\
\hline mik-208 & 1 & CCGUAGGCCGUUGGAAGCGAUC & 21 & $\mathrm{Mm}$ & - & - & - & - & - & - & - \\
\hline miR-209 & 1 & UUAGUAUGGUJGCCUIJCCAA & 20 & $\mathrm{Mm}$ & - & - & - & - & - & - & + \\
\hline miR-210 & 1 & UCGUCOCGAGACCGAITUAUTÜ & 21 & $\mathrm{Mm}$ & . & - & - & - & - & - & - \\
\hline mik-211 & 1 & GACCUGAGAGGGUGAUCGGCCAC & 23 & $\mathrm{Mn}$ & - & . & . & . & . & . & . \\
\hline mik-212 & 1 & AGGCAUGGCCAGGUUGAAGCGAGG & 24 & $\mathrm{Mm}$ & - & - & - & - & - & - & . \\
\hline miR-213 & 1 & GUACUIJAGUAGAGCAGCCAC & 20 & $\mathrm{Mm}$ & - & . & . & . & - & - & - \\
\hline$m i R-214$ & 1 & GGCGUAAAGGGAGCGUACGCOGAU & 24 & Mir & - & - & - & . & . & - & . \\
\hline miR-215 & $i$ & $\triangle G \triangle C C C A C C A G G C G U U C G G C C$ & 21 & $\mathrm{Mm}$ & - & - & - & - & - & - & - \\
\hline$m i R=216$ & 1 & IЛUАGAUJGAGAUAАCAGGTUUUU & 22 & $\mathrm{Mm}$ & - & - & - & - & - & - & - \\
\hline$m i R-217$ & 1 & CAAAGCAGCAGIJATJCGCCTI & 19 & $\mathrm{Mm}$ & . & . & - & - & - & - & - \\
\hline mik-218 & 1 & AUGCCUGUCGGUUACUGCCUGCU & 23 & $\mathrm{Mm}$ & - & - & - & . & . & - & + \\
\hline mik-219 & 2 & CAGACAGGGUGUACAUGACCUIJ & 22 & $\mathrm{Mm}$ & - & - & - & . & . & + & . \\
\hline
\end{tabular}

The short (22-25 nt) RNAs associated with miRNPs in MN-1 cells were cloned as previously described (Elbashir et al. 2001), and a total of 43 clones were sequenced. miRNAs in bold letters were previously shown to associate with miRNPs in HeLa cells. The miRNA sequences are shown 5' to '3'. The source (Hs; Homo sapiens, Mm; Mus musculus) indicates the species of the cell line from which the miRNAs were identified. In this column, - indicates miRNAs identified by sequence homology in the human genome. (Chr.); chromosomal localization of the miRNA in the human genome. Dr; Danio rerio, Fr; Fugu rubripes, Dm; Drosophila melanogaster, Ce; Caenorhabditis elegans, Mm; Mus musculus, Rn; Rattus norvegicus. + indicates fully conserved miRNAs, and + in red color represents conserved miRNAs containing one or two mismatches.

by northern blotting, it is not certain whether these are novel neuronal-specific or ubiquitously miRNAs. The miRNAs with an entry in the human genome database are predicted to fold into stem-loop structures with surrounding genomic sequences (Fig. 2). The predicted secondary structure of the miRNA precursors localized on more than one chromosome or that can be mapped in the genome of other species is often partially conserved (data not shown). Two of the miRNAs, miR-23b and miR-27b, were found as part of a novel cluster in the human genome on chromosome 9 (Fig. 3A; solid boxes). In addition, two computerpredicted putative miRNA precursors were found surrounding miR-27b (dashed boxes in Fig. 3).

Interestingly, miR-175 from Weri cells, which is located on the X chromosome in humans and is conserved in $D$. melanogaster and M. musculus, was also found as part of a longer human Expressed Sequence Tag (EST). This EST contains the miR-175 miRNA precursor and possibly another miRNA precursor that was computer-predicted, and encodes a putative isoform of the epsilon subunit of the gamma-aminobutyric acid (GABA) A receptor (Fig. 3A; Wilke et al. 1997). This receptor is a multisubunit chloride channel that inhibits synaptic transmission in the central nervous system. The gene locus of the epsilon subunit is a candidate region for two neurologic diseases: early-onset parkinsonism (Waisman syndrome; Gregg et al. 1991), and X-linked mental retardation (MRX3; Gedeon et al. 1991). Thus, it will be of interest to determine whether miR-175 synthesis or activity are affected and whether deregulation of this miRNA plays a role in the development of these diseases.

\section{Two distinct subfamilies of miRNAs associate with miRNPs in neuronal cells}

Analysis of the miRNPs indicates that they contain a large family of highly conserved miRNAs in this cell type (Fig. 3B). This miRNA family encompasses at least nine mem- 

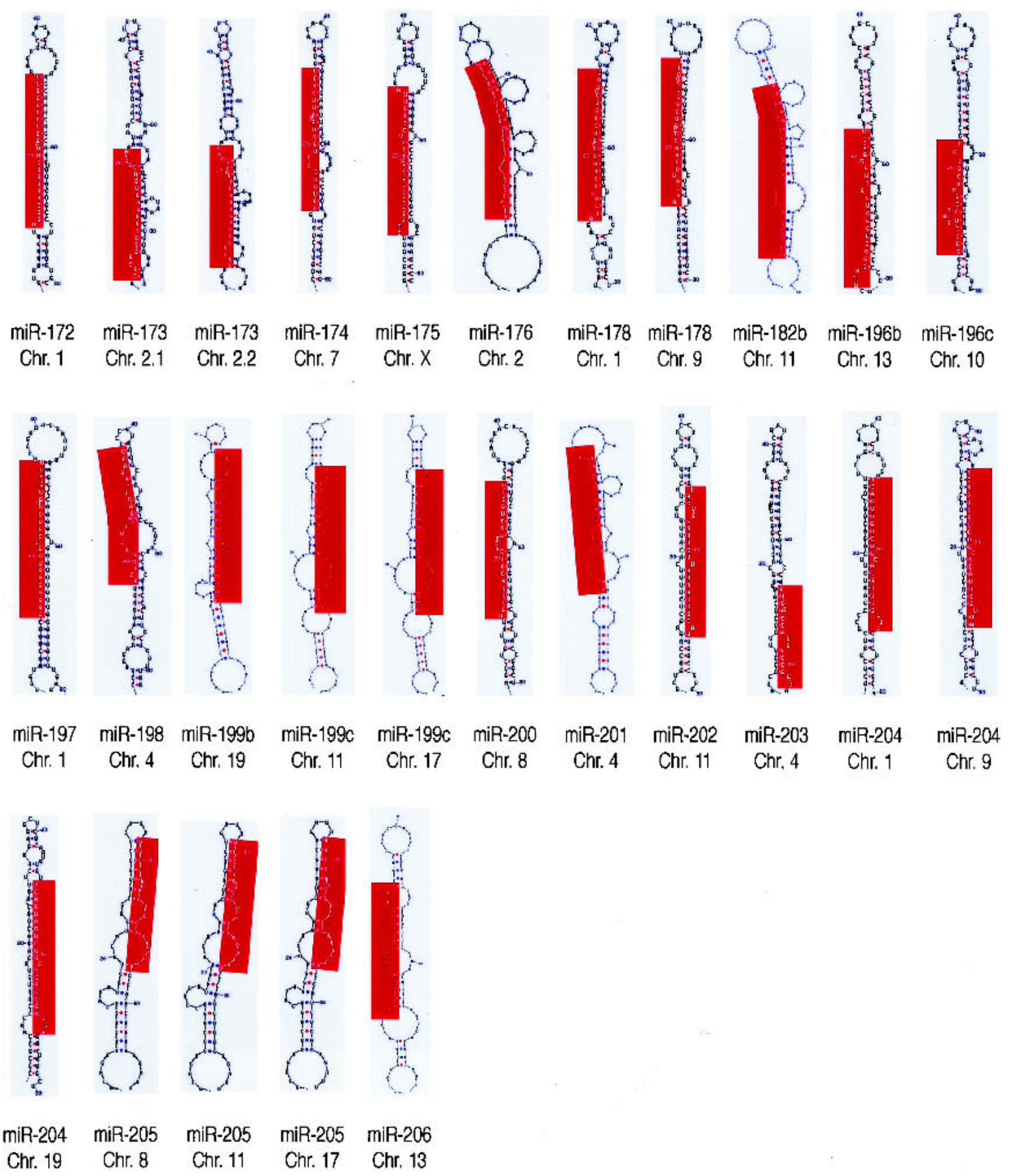

FIGURE 2. Predicted secondary structures of the novel human miRNA putative precursors. Human genomic sequences upstream and downstream of the novel miRNAs were folded with the computer program mfold. Predicted secondary structures are shown $5^{\prime}$ to $3^{\prime}$. Red areas represent the mature miRNA. Chromosome number represents the localization of the miRNA in the human genome.

bers, including miR-182a, miR-182b, miR-188, and miR207, which are described herein. This result suggests that these miRNPs may play an important role in the maturation and/or delivery of their miRNAs to a common class of putative RNA targets in neuronal cells. In addition, several miRNAs with homologous $5^{\prime}$ ends were found in miRNPs (Fig. 3C). Most members of this miRNA class were associ- ated with miRNPs identified from the neuronal cells, including the novel miR-29c, miR-187, and miR-217. The 5' end of several miRNAs was recently found to be complementary to the $\mathrm{K}$ box, Brd box, and GY box motifs found in the 3' UTR of basic helix-loop-helix (bHLH) repressors and the Bearded (Brd) family members (Lai 2002). The K and Brd box sequences mediate negative posttranscriptional 
mRNA regulation by affecting the polyadenylation status of transcripts, resulting in decreased stability and translational efficiency of the mRNA (Lai and Posakony 1997; Lai et al.
1998). Thus, the identification of these miRNA families should help in the identification of putative mRNA targets and in the elucidation of their functions.
A

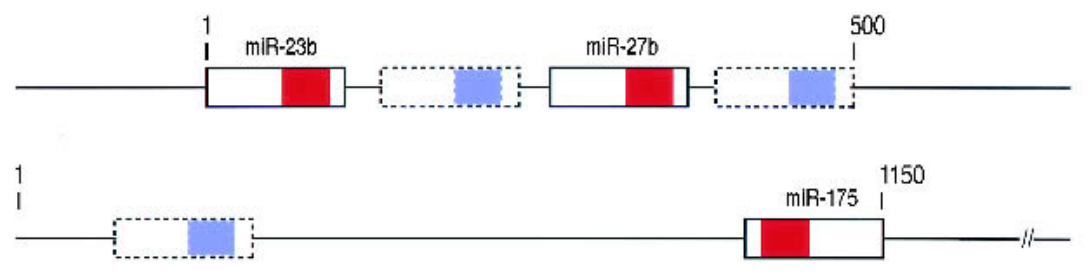

Chr. X

B
Chr. 9

\section{MATERIALS AND METHODS}

\section{Cell culture and cell extract preparation}

MN-1 cells were grown in Dulbecco's modified Eagle's medium (DMEM) supplemented with $10 \%$ fetal bovine serum (FBS; complete DMEM). Weri cells were grown in DMEM supplemented with $10 \%$ fetal bovine serum. At $80 \%$ confluence, cells $\left(1 \times 10^{7}\right)$ were collected by centrifugation at $1000 \mathrm{~g}$ for $15 \mathrm{~min}$ at $4^{\circ} \mathrm{C}$. The cell pellet was washed with cold phosphate-buffered saline (PBS), and with RSB 200 (20 mM Tris- $\mathrm{HCl}$ pH 7.4, $2.5 \mathrm{mM}$ magnesium chloride, $200 \mathrm{mM}$ sodium chloride). Cells were resuspended in one volume of lysis buffer (RSB 200 containing $0.05 \%$ NP-40, RNAsin (1 $\mathrm{U} / \mu \mathrm{L})$ and protease inhibitors (Complete $^{\mathrm{TM}}$; Roche), and disrupted by brief sonication. Extract was clarified by centrifugation at $11,000 \mathrm{~g}$ for $15 \mathrm{~min}$ at $4^{\circ} \mathrm{C}$.

\section{RNA immunoprecipitation, 3 '-end labeling, and miRNA cloning}

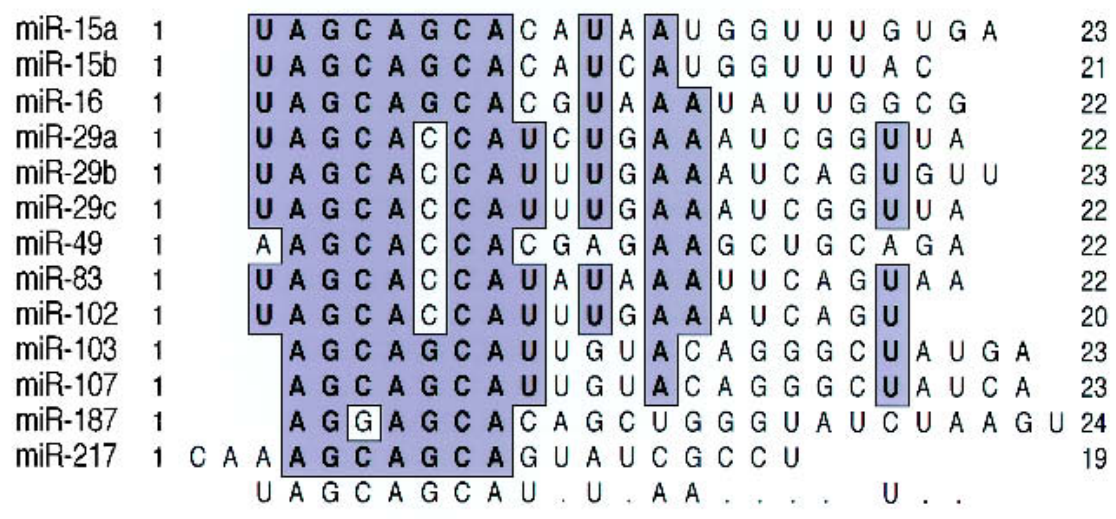

CONSENSUS:

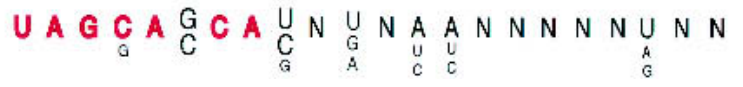

FIGURE 3. Novel miRNA clusters and families of miRNA paralogs associated with miRNPs in neuronal cells. (A) Novel miRNA clusters. The putative precursors of identified miRNAs are presented as solid boxes, and the mature miRNAs identified in the study are shown in red. Computer-predicted putative miRNA precursors are presented as dashed boxes, and the predicted mature miRNAs are shown in light blue. The chromosomal localization in the human genome is indicated on the right. The size of the region containing the miRNAs is indicated at the top of each cluster. $(B)$ miRNPs contain a conserved miRNA family in neuronal cells. miRNA family members associated with miRNPs in neuronal cells are aligned. The names of miRNAs are indicated on the left. miRNA length is shown at the end of each miRNA. Conserved residues are in bold letters and gray shaded areas. Consensus is shown at the bottom: Nucleotides shown in red were invariable. (C) miRNPs contain a class of miRNAs with homologous 5' ends in neuronal cells. miRNA class members with homologous $5^{\prime}$ ends are aligned. The names of miRNAs are indicated on the left. miRNA length is shown at the end of each miRNA. Conserved residues are in bold letters and gray shaded areas. Consensus is shown at the bottom: Nucleotides shown in red were invariable.
For immunoprecipitation, cell extract was incubated for $1 \mathrm{~h}$ at $4^{\circ} \mathrm{C}$ with either normal mouse serum (NMS) as control, or with anti-Gemin3 (11G9) antibodies immobilized on GammaBind ${ }^{\mathrm{TM}} \mathrm{G}$ Seph$\operatorname{arose}^{\mathrm{TM}}$ (Amersham Pharmacia Biotech). Immunoprecipitates were washed five times with lysis buffer, treated with DNAse I ( $0.5 \mathrm{U} / \mu \mathrm{L}$; Roche) for $15 \mathrm{~min}$ at $30^{\circ} \mathrm{C}$, followed by proteinase $\mathrm{K}$ digestion $\left(0.2 \mu \mathrm{g} / \mu \mathrm{L}\right.$; Roche) for $30 \mathrm{~min}$ at $37^{\circ} \mathrm{C}$. RNA was extracted with phenol followed by two phenol/chloroform extractions and ethanol precipitation. The RNA was $3^{\prime}$-end labeled with $\left[5^{\prime}-{ }^{32} \mathrm{P}\right]-\mathrm{pCp}$ and analyzed on a denaturing $15 \%$ polyacrylamide gel. The $\sim 22-n t$ miRNAs were cloned by using the protocol developed by Elbashir and coworkers (2001).

\section{RNA analysis}

miRNA sequences were determined by automated DNA-cycle sequencing. Chromosomal locations and genomic se- 
quences of the novel miRNAs were identified by searching various genomes with the Basic Local Alignment Sequence Tool (BLAST ${ }^{\circledR}$ ) algorithm, available at the National Center for Biotechnology Information (NCBI). Secondary structures of the likely precursors of the novel miRNAs were predicted by folding upstream and downstream genomic miRNA sequences with the computer program mfold (Zuker et al. 1999). miRNA alignments were established with the macvector program.

\section{ACKNOWLEDGMENTS}

We thank the members of our laboratory, especially Drs. Severine Massenet and Sergey Paushkin, for stimulating discussions and comments on this manuscript. We also thank Gina Daly for secretarial assistance. This work was supported by grants from the Canadian Institute of Health Research (J.D.), from the NIH (J.D., Z.M., G.D.), and from the Association Française contre les Myopathies (AFM) to G.D. G.D. is an Investigator of the Howard Hughes Medical Institute.

The publication costs of this article were defrayed in part by payment of page charges. This article must therefore be hereby marked "advertisement" in accordance with 18 USC section 1734 solely to indicate this fact.

Received September 17, 2002; accepted October 10, 2002.

\section{REFERENCES}

Ambros, V. and Horvitz, H.R. 1984. Heterochronic mutants of the nematode Caenorhabditis elegans. Science 226: 409-416.

Baccon, J., Pellizzoni, L., Rappsilber, J., Mann, M., and Dreyfuss, G. 2002. Identification and characterization of Gemin7, a novel component of the SMN complex. J. Biol. Chem. 277: 31957-31962.

Brooks, B.P., Paulson, H.L., Merry, D.E., Salazar-Grueso, E.F., Brinkmann, A.O., Wilson, E.M., and Fischbeck, K.H. 1997. Characterization of an expanded glutamine repeat androgen receptor in a neuronal cell culture system. Neurobiol. Dis. 3: 313-323.

Charroux, B., Pellizzoni, L., Perkinson, R.A., Shevchenko, A., Mann, M., and Dreyfuss, G. 1999. Gemin3: A novel DEAD box protein that interacts with $\mathrm{SMN}$, the spinal muscular atrophy gene product, and is a component of gems. J. Cell Biol. 147: 1181-1194.

Charroux, B., Pellizzoni, L., Perkinson, R.A., Yong, J., Shevchenko, A., Mann, M., and Dreyfuss, G. 2000. Gemin4. A novel component of the SMN complex that is found in both gems and nucleoli. J. Cell Biol. 148: $1177-1186$.

Elbashir, S.M., Lendeckel, W., and Tuschl, T. 2001. RNA interference is mediated by 21- and 22-nucleotide RNAs. Genes \& Dev. 15: 188-200.

Fischer, U., Liu, Q., and Dreyfuss, G. 1997. The SMN-SIP1 complex has an essential role in spliceosomal snRNP biogenesis. Cell 90: 1023-1029.

Gedeon, A., Kerr, B., Mulley, J., and Turner, G. 1991. Localisation of the MRX3 gene for non-specific X linked mental retardation. J. Med. Genet. 28: 372-377.

Gregg, R.G., Metzenberg, A.B., Hogan, K., Sekhon, G., and Laxova, R. 1991. Waisman syndrome, a human X-linked recessive basal ganglia disorder with mental retardation: Localization to Xq27.3-qter. Genomics 9: 701-706.

Gubitz, A.K., Mourelatos, Z., Abel, L., Rappsilber, J., Mann, M., and Dreyfuss, G. 2002. Gemin5, a novel WD repeat protein component of the SMN complex that binds Sm proteins. J. Biol. Chem. 277: 5631-5636.

Hutvagner, G., McLachlan, J., Pasquinelli, A.E., Balint, E., Tuschl, T., and Zamore, P.D. 2001. A cellular function for the RNA-interference enzyme Dicer in the maturation of the let-7 small temporal RNA. Science 293: 834-838.

Jones, K.W., Gorzynski, K., Hales, C.M., Fischer, U., Badbanchi, F., Terns, R.M., and Terns, M.P. 2001. Direct interaction of the spinal muscular atrophy disease protein SMN with the small nucleolar RNA-associated protein fibrillarin. J. Biol. Chem. 276: 38645-38651.

Lagos-Quintana, M., Rauhut, R., Lendeckel, W., and Tuschl, T. 2001. Identification of novel genes coding for small expressed RNAs. Science 294: 853-858.

Lagos-Quintana, M., Rauhut, R., Yalcin, A., Meyer, J., Lendeckel, W., and Tuschl, T. 2002. Identification of tissue-specific microRNAs from mouse. Curr. Biol. 12: 735-739.

Lai, E.C. 2002. Micro RNAs are complementary to 3' UTR sequence motifs that mediate negative post-transcriptional regulation. Nat. Genet. 30: 363-364.

Lai, E.C. and Posakony, J.W. 1997. The Bearded box, a novel 3' UTR sequence motif, mediates negative post-transcriptional regulation of Bearded and Enhancer of split Complex gene expression. Development 124: 4847-4856.

Lai, E.C., Burks, C., and Posakony, J.W. 1998. The K box, a conserved $3^{\prime}$ UTR sequence motif, negatively regulates accumulation of enhancer of split complex transcripts. Development 125: 4077-4088.

Lau, N.C., Lim, L.P., Weinstein, E.G., and Bartel, D.P. 2001. An abundant class of tiny RNAs with probable regulatory roles in Caenorhabditis elegans. Science 294: 858-862.

Lee, R.C. and Ambros, V. 2001. An extensive class of small RNAs in Caenorhabditis elegans. Science 294: 862-864.

Liu, Q., Fischer, U., Wang, F., and Dreyfuss, G. 1997. The spinal muscular atrophy disease gene product, SMN, and its associated protein SIP1 are in a complex with spliceosomal snRNP proteins. Cell 90: 1013-1021.

McFall, R.C., Sery, T.W., and Makadon, M. 1977. Characterization of a new continuous cell line derived from a human retinoblastoma. Cancer Res. 37: 1003-1010.

Meister, G., Eggert, C., Buhler, D., Brahms, H., Kambach, C., and Fischer, U. 2001. Methylation of Sm proteins by a complex containing PRMT5 and the putative $\mathrm{U}$ snRNP assembly factor pICln. Curr. Biol. 11: 1990-1994.

Melki, J. 1997. Spinal muscular atrophy. Curr. Opin. Neurol. 10: 381-385.

Mourelatos, Z., Abel, L., Yong, J., Kataoka, N., and Dreyfuss, G. 2001. SMN interacts with a novel family of hnRNP and spliceosomal proteins. EMBO J. 20: 5443-5452.

Mourelatos, Z., Dostie, J., Paushkin, S., Sharma, A., Charroux, B., Abel, L., Rappsilber, J., Mann, M., and Dreyfuss, G. 2002. miRNPs: A novel class of ribonucleoproteins containing numerous microRNAs. Genes \& Dev. 16: 720-728.

Paushkin, S., Gubitz, A.K., Massenet, S., and Dreyfuss, G. 2002. The SMN complex, an assemblyosome of ribonucleoproteins. Curr. Opin. Cell Biol. 14: 305-312.

Pellizzoni, L., Kataoka, N., Charroux, B., and Dreyfuss, G. 1998. A novel function for SMN, the spinal muscular atrophy disease gene product, in pre-mRNA splicing. Cell 95: 615-624.

Pellizzoni, L., Baccon, J., Charroux, B., and Dreyfuss, G. 2001a. The survival of motor neurons (SMN) protein interacts with the snoRNP proteins fibrillarin and GAR1. Curr. Biol. 11: 1079-1088.

Pellizzoni, L., Baccon, J., Rappsilber, J., Mann, M., and Dreyfuss, G. 2002. Purification of native survival of motor neurons complexes and identification of Gemin6 as a novel component. J. Biol. Chem. 277: 7540-7545.

Pellizzoni, L., Charroux, B., Rappsilber, J., Mann, M., and Dreyfuss, G. 2001b. A functional interaction between the survival motor neuron complex and RNA polymerase II. J. Cell Biol. 152: 75-85.

Reinhart, B.J., Slack, F.J., Basson, M., Pasquinelli, A.E., Bettinger, J.C., Rougvie, A.E., Horvitz, H.R., and Ruvkun, G. 2000. The 21nucleotide let-7 RNA regulates developmental timing in Caenorhabditis elegans. Nature 403: 901-906.

Salazar-Grueso, E.F., Kim, S., Kim, H. 1991. Embryonic mouse spinal cord motor neuron hybrid cells. Neuroreport 2: 505-508.

Wilke, K., Gaul, R., Klauck, S.M., and Poustka, A. 1997. A gene in human chromosome band Xq28 (GABRE) defines a putative new subunit class of the GABAA neurotransmitter receptor. Genomics 45: 1-10.

Zuker, M., Mathews, D.H., and Turner, D.H. 1999. Algorithms and thermodynamics for RNA secondary structure prediction: A practical guide. Kluwer Academic, Dordrecht, The Netherlands. 
RNA 9: $180-186(2003)$

\section{Numerous microRNPs in neuronal cells containing novel microRNAs}

\section{JOSÉE DOSTIE, ZISSIMOS MOURELATOS, MICHAEL YANG, ANUP SHARMA, and GIDEON DREYFUSS}

We wish to revise the designation of the microRNAs (miRNAs) reported in Tables 1 and 2 of the original manuscript. The simultaneous publication of numerous new miRNA sequences in the same issue of RNA (Lagos-Quintanas, M., Rauhut, R., Meyer, J., Borkhardt, A., and Tuschl, T. 2003. New microRNAs from mouse and human. RNA 9: 175-179), and the report of several miRNA sequences which were not available at the time of submission of our manuscript resulted in an extensive overlap in the designation of many of the miRNAs we reported. To rectify this, we changed the designations of many of the miRNAs included in Tables 1 and 2 and adopted the designation used by others. The novel miRNAs-those not included in publications by others-are numbered sequentially beginning with miRNA 224. In addition, many of the miRNAs we

Table 1. miRNA and miRNA-like sequences associated with miRNPs in the Weri human neuronal cell line

\begin{tabular}{|c|c|c|c|c|c|c|c|c|c|c|c|}
\hline \multirow[b]{2}{*}{ miRNA } & \multirow[b]{2}{*}{ Number of } & \multirow[b]{2}{*}{$\begin{array}{l}\text { miRNA sequence } \\
\text { clones }\end{array}$} & \multirow[b]{2}{*}{ Size } & \multirow[b]{2}{*}{$\begin{array}{l}\text { Source } \\
\text { (nt) }\end{array}$} & \multicolumn{7}{|c|}{ Predicted Precursors } \\
\hline & & & & & Hs (Chr) & Dr & $\mathrm{Fr}$ & Dm & $\mathrm{Ce}$ & $\mathrm{Mm}$ & Rn \\
\hline let-7a & 1 & UGAGGUAGUAGGUUGUAUAGUU & 22 & Hs & $+(9,11,22)$ & - & + & + & + & + & + \\
\hline $\operatorname{miR}-15 \mathrm{a}$ & 1 & UAGCAGCACAUAAUGGUUUGUGA & 23 & $\mathrm{Hs}$ & $+\quad(13)$ & + & + & - & - & - & - \\
\hline $\mathrm{miR}-15 \mathrm{~b}$ & 1 & UAGCAGCACAUCAUGGUUUAC & 21 & $\mathrm{Hs}, \mathrm{Mm}$ & $+(3)$ & - & - & - & - & + & - \\
\hline miR-19a & 4 & UGUGCAAAUCUAUGCAAAACUGA & 23 & Hs & $+\quad(13)$ & - & + & - & + & - & + \\
\hline miR-19b & 4 & UGUGCAAAUCCAUGCAAAACUGA & 23 & $\mathrm{Hs}$ & $+(13, X)$ & - & + & - & - & - & + \\
\hline miR-20 & 8 & UAAAGUGCUUAUAGUGCAGGUAG & 23 & $\mathrm{Hs}$ & $+\quad(13)$ & - & + & - & - & - & + \\
\hline miR-21 & 1 & AGUUAGCUUAUCAGACUGAUGUUGA & 25 & $\mathrm{Hs}$ & $+\quad(13)$ & - & + & - & - & - & + \\
\hline $\operatorname{miR}-27 b$ & 1 & GUUCACAGUGGCUAAGUUCUG & 21 & $\mathrm{Hs}, \mathrm{Mm}$ & $+\quad(9)$ & - & + & - & - & + & + \\
\hline miR-29a & 1 & UAGCACCAUCUGAAAUCGGUUA & 22 & Hs & $+(7.1,7.2)$ & - & - & - & - & + & + \\
\hline miR-29c & 1 & UAGCACCAUUUGAAAUCGGUUA & 22 & Hs & $+(1)$ & - & + & - & - & - & + \\
\hline miR-34 & 2 & UGGCAGUGUCUUAGCUGGUUGUU & 23 & $\mathrm{Hs}$ & (1) & - & + & - & - & + & - \\
\hline miR-91 & 5 & CAAAGUGCUUACAGUGCAGGUAG & 23 & Hs & $+\quad(13)$ & - & + & - & - & - & + \\
\hline miR-92 & 3 & UAUUGCACUUGUCCCGGCCUGU & 22 & Hs & $+(13, X)$ & - & + & + & - & - & + \\
\hline miR-93 & 1 & AAAGUGCUGUUCGUGCAGGUAG & 22 & Hs & $+(7.1,7.2)$ & - & + & - & - & + & - \\
\hline miR-94 & 1 & UAAAGUGCUGACAGUGCAGAUA & 22 & Hs & $+(7.1,7.2)$ & - & - & - & - & + & - \\
\hline miR-106 & 1 & AAAAGUGCUUACAGUGCAGGUAGC & 24 & Hs & $+\quad(X)$ & - & + & - & - & - & - \\
\hline miR-124a & 3 & UAAGGCACGCGGUGAAUGCCAA & 22 & Hs & $+(8.1,8.2,20)$ & - & + & + & + & - & - \\
\hline miR-181 & 1 & AACAUUCAACGCUGUCGGUGAGUU & 25 & $\mathrm{Hs}, \mathrm{Mm}$ & $+\quad(1,9)$ & - & + & - & - & + & + \\
\hline miR-183 & 1 & UAUGGCACUGGUAGAAUUCACU & 22 & Hs & $(T)$ & + & + & + & - & - & - \\
\hline miR-224 & 1 & CAAGUCACUAGUGGUUCCGUUUA & 23 & Hs & $+(\mathrm{X})$ & - & - & + & - & + & - \\
\hline miR-Lk-1 & 1 & GGACUGCCUCAGCUGUGC & 18 & Hs & (2) & - & - & - & - & . & - \\
\hline $\operatorname{miR}-\mathrm{Lk}-2$ & 1 & GUGUCCUAAGGUGAGCUCAG & 20 & Hs & $(8)$ & - & - & - & + & + & + \\
\hline miR-Lk-3 & 1 & GGUUGAUAGGUCGGGGGUGUAA & 22 & $\mathrm{Hs}, \mathrm{Mm}$ & - & - & - & - & - & - & - \\
\hline miR-Lk-4 & 1 & AUUUCAGGUGAAGUUUCAAGAGUC & 24 & $\mathrm{Hs}, \mathrm{Mm}$ & - & - & - & - & - & - & - \\
\hline miR-Lk-5 & 1 & GUGCUAGGGAUUGGGGCUUG & 20 & $\mathrm{Hs}, \mathrm{Mm}$ & - & - & - & - & - & + & + \\
\hline miR-Lk-6a & 1 & CAAAGUGCUGUUAGUGCAGGUAG & 23 & Hs & - & - & + & - & - & - & + \\
\hline miR-Lk-6b & - & CAAAGUGCUGUUAUUGCAGG & 20 & - & (11) & - & - & - & - & - & + \\
\hline miR-Lk-7 & 2 & ACUACGAAUGAUAACAUCCGUGG & 23 & Hs & - & - & - & - & - & - & - \\
\hline miR-Lk-8 & 1 & AUGCAAGUCGAGCUUGAAGUUUC & 23 & Hs & - & - & - & - & - & - & - \\
\hline miR-Lk-9 & 1 & AUCGUUAUUAUCGAUGGCGUGA & 22 & Hs & - & - & - & - & . & - & - \\
\hline miR-Lk-10 & 1 & CGGCCUUAGUCGUCGGGGUGAUU & 23 & Hs & - & - & - & - & - & - & - \\
\hline miR-Lk-11 & 1 & AGGAGCACAGCUGGGUAUCUAAGU & 24 & Hs & - & - & - & - & - & - & - \\
\hline miR-Lk-12 & 1 & CAACCUUGGGAUACCACCCUGUA & 23 & Hs & - & - & - & - & - & - & - \\
\hline miR-Lk-13 & 1 & CGUAGACCCGAAACCGGGUGAC & 22 & Hs & - & - & - & - & - & - & - \\
\hline miR-Lk-14 & 1 & UACCGCAUAAUGUUGAAAGAUGG & 23 & Hs & - & - & - & - & - & - & - \\
\hline miR-Lk-15 & 1 & CGGUUCAUACCCGAAGGGUCGCAA & 24 & Hs & - & - & - & - & - & . & - \\
\hline miR-Lk-16 & 1 & AUAACGUUGAAAGAUGGCAUC & 21 & Hs & - & - & - & - & - & - & - \\
\hline miR-Lk-17 & 1 & CGAGCCGUCGUAGACCACGACGUU & 24 & Hs & - & - & - & - & - & - & - \\
\hline miR-Lk-18 & 1 & GCCGUCGUCGACGAGUGCACUU & 22 & Hs & - & - & - & - & - & - & - \\
\hline miR-Lk-19 & 1 & CAAAGUGCUUACAGUUCAGGUAG & 23 & Hs & - & - & - & - & - & - & - \\
\hline
\end{tabular}

The short (22-25 nt) RNAs associated with miRNPs in Weri cells were cloned as previously described (Elbashir et al., 2001), and a total of 64 clones were sequenced. miRNAs in bold letters were previously shown to associate with miRNPs in HeLa cells. miR-Lk-number represents small RNA sequences, identified in the miRNP complexes, that cannot be classified as miRNAs under the novel classification code for miRNAs. The sequences are shown $5^{\prime}$ to $3^{\prime}$. The source (Hs; Homo sapiens, Mm; Mus musculus) indicates the species of the cell line from which the RNAs were identified. In this column, - indicates RNAs identified by sequence homology in the human genome. (Chr); chromosomal localization of the miRNA in the human genome. Dr; Dario rerio, Fr; Fugu rubripes, Dm; Drosophila melanogaster, Ce; Caenorhabditis elegans, Mm; Mus musculus, Rn; Rattus norvegicus; + indicates fully conserved RNAs, and + represents conserved RNAs containing one or two mismatches. 
reported do not, in the absence of additional data, fulfill the stringent criteria suggested as guidelines for classification of newly discovered RNAs as miRNAs as was recently published (Ambros, V., Bartel, B., Bartel, D.P., Burge, C.B., Carrington, J.C., Chen, X., Dreyfuss, G., Eddy, S.R., Griffiths-Jones, S., Marshall, M., et al. 2003. A uniform system for microRNA annotation. RNA 9: 277-279). However, we are confident in the authenticity of these RNAs as assessed by co-immunoprecipitation with anti-Gemin3 antibodies and sequence determination often from multiple clones. In light of this, we refer to these RNAs as miRNA-like (miRNA-Lk-\#) in the revised Tables. Four RNAs-miR-173, miR-196a, miR-196b, and miR-196c - were deleted from the Tables because their relevance to the corresponding genome could not be confirmed by additional criteria. The new designations of the novel miRNAs will be corrected in the NCBI database. We regret any potential confusion in nomenclature that our original publication may have caused. All the conclusions of the paper remain.

Table 2. miRNA and miRNA-like sequences associated with miRNPs in the MN-1 mouse neuronal cell line

\begin{tabular}{|c|c|c|c|c|c|c|c|c|c|c|c|}
\hline \multirow[b]{2}{*}{ miRNA } & \multirow[b]{2}{*}{$\begin{array}{c}\text { Number of } \\
\text { clones }\end{array}$} & \multirow[b]{2}{*}{ miRNA sequence } & \multirow[b]{2}{*}{$\begin{array}{l}\text { Size } \\
\text { (nt) }\end{array}$} & \multirow[b]{2}{*}{ Source } & \multicolumn{7}{|c|}{ Predicted Precursors } \\
\hline & & & & & Hs (Chr.) & Dr & Fr & $\mathrm{Dm}$ & $\mathrm{Ce}$ & $\mathrm{Mm}$ & Rn \\
\hline miR-16 & 1 & UAGCAGCACGUAAAUAUUGGCG & 22 & $\mathrm{Mm}$ & $+(3,13)$ & - & + & - & - & + & - \\
\hline miR-19a & 1 & UGUGCAAAUCUAUGCAAAACUGA & 23 & $\mathrm{Mm}$ & $+\quad(13)$ & - & + & - & + & - & + \\
\hline miR-19b & 2 & UGUGCAAAUCCAUGCAAAACUGA & 23 & $\mathrm{Mm}$ & $+(13, X)$ & - & + & - & - & - & + \\
\hline miR-21 & 1 & UAGCUUAUCAGACUGAUGUUGAC & 22 & $\mathrm{Mm}$ & $+(13)$ & - & + & - & - & - & + \\
\hline miR-22 & 1 & AAGCUGCCAGUUGAAGAACUG & 21 & $\mathrm{Mm}$ & $+\quad(17)$ & - & - & - & - & + & + \\
\hline $\mathrm{miR}-23 \mathrm{~b}$ & 2 & AUCACAUUGCCAGGGAUUACCAC & 23 & $\mathrm{Mm}$ & $+(9)$ & - & + & - & - & - & - \\
\hline miR-24 & 2 & UGGCUCAGUUCAGCAGGAACAGA & 23 & $\mathrm{Mm}$ & $+(9,19)$ & - & + & - & - & + & + \\
\hline $\mathrm{miR}-26 \mathrm{~b}$ & 1 & UUCAAGUAAUUCAGGAUAGGUUU & 23 & $\mathrm{Mm}$ & $+\quad(2)$ & - & + & - & - & + & + \\
\hline miR-27 & 2 & UUCACAGUGGCUAAGUUCCGC & 21 & $\mathrm{Mm}$ & $+\quad(19)$ & - & + & - & - & + & + \\
\hline miR-30d & 1 & UGUAAACAUCCCCGACUGGAA & 22 & $\mathrm{Mm}$ & $+(8)$ & - & + & - & - & + & - \\
\hline miR-103 & 1 & AGCAGCAUUGUACAGGGCUAUGA & 23 & $\mathrm{Mm}$ & $+(5,10,20)$ & - & + & - & - & + & + \\
\hline $\operatorname{miR}-130$ & 1 & CAGUGCAAUGUUAAAAGGGCAU & 22 & $\mathrm{Mm}$ & $+(11)$ & - & + & - & - & - & + \\
\hline miR-186 & 1 & CAAAGAAUUCUCCUUUUGGGGUU & 23 & $\mathrm{Mm}$ & $+\quad(1)$ & - & - & - & - & - & - \\
\hline miR-199-as & 1 & ACAGUAGUCUGCACAUUGGUUA & 22 & $\mathrm{Mm}$ & $+(1,9.19)$ & - & + & - & - & + & + \\
\hline $\operatorname{miR}-20$ & 1 & ACUGGACUUGGAGUCAAAAGG & 21 & $\mathrm{Mm}$ & (4) & - & - & - & - & - & - \\
\hline $\operatorname{miR}-21$ & 1 & CCUGGGUGCCAAGUUUUGAC & 20 & $\mathrm{Mm}$ & (4) & - & - & - & - & - & - \\
\hline miR-Lk-22a & 1 & UGAUUCGGUGGGUGGUGGUGC & 21 & $\mathrm{Mm}$ & - & - & - & - & - & - & - \\
\hline miR-Lk-22b & - & UGAUUCCGUGGGUGGUGGUGC & 21 & - & $+\quad(19)$ & - & - & - & - & - & + \\
\hline miR-Lk-22c & - & UGAUUCUGUGGGUGGUGGUGC & 21 & - & $+(11,17)$ & - & - & - & - & + & + \\
\hline miR-Lk-23 & 1 & GUGCUAGGAUUGGGGCU & 17 & $\mathrm{Mm}$ & $+\quad(4)$ & - & - & - & - & - & + \\
\hline miR-Lk-24 & 1 & AGCCAAUGGUGCGAAGCUA & 19 & $\mathrm{Mm}$ & $+(8,11,17)$ & - & - & - & - & + & - \\
\hline miR-Lk-25 & 1 & UGUUGAAAAAGCAUGGGAUG & 20 & $\mathrm{Mm}$ & $+\quad(13)$ & - & - & - & - & + & + \\
\hline miR-Lk-26 & 1 & UAAAGUGCUGACAGCUCAGAUA & 22 & $\mathrm{Mm}$ & - & - & - & - & - & - & - \\
\hline miR-Lk-27 & 1 & CCGUAGGCCGUUGAAGCGAUC & 21 & $\mathrm{Mm}$ & - & - & - & - & - & - & - \\
\hline miR-Lk-28 & 1 & UUAGUAUGGUUGCCUUCCAA & 20 & $\mathrm{Mm}$ & - & - & - & - & - & . & + \\
\hline miR-Lk-29 & 1 & UCGUCCCGAGACCGAUUAUUU & 21 & $\mathrm{Mm}$ & . & - & . & - & - & - & - \\
\hline miR-Lk-30 & 1 & GACCUGAGAGGGUGAUCGGCCAC & 23 & $\mathrm{Mm}$ & - & - & - & - & - & ـ & - \\
\hline miR-Lk-31 & 1 & AGGCAUGGCCAGGUUGAAGCGAGG & 24 & $\mathrm{Mm}$ & - & - & - & - & - & - & - \\
\hline miR-Lk-32 & 1 & GUACUUAGUAGAGCAGCCAC & 20 & $\mathrm{Mm}$ & - & - & - & - & - & - & - \\
\hline miR-Lk-33 & 1 & GGCGUAAAGGGAGCGUACGCGGAU & 24 & $\mathrm{Mm}$ & - & - & - & - & - & - & - \\
\hline miR-Lk-34 & 1 & AGACCCACCAGGCGUUCGGCC & 21 & $\mathrm{Mm}$ & - & - & - & - & - & - & - \\
\hline miR-Lk-35 & 1 & UUAGAUGAGAUAACAGGUUUCU & 22 & $\mathrm{Mm}$ & - & - & - & - & - & - & - \\
\hline miR-Lk-36 & 1 & CAAAGCAGCAGUAUCGCCU & 19 & $\mathrm{Mm}$ & - & - & - & - & - & - & - \\
\hline
\end{tabular}

The short (22-25 nt) RNAs associated with miRNPs in MN-1 cells were cloned as previously described (Elbashir et al.,2001), and a total of 43 clones were sequenced, miRNAs in bold letters were previously shown to associate with miRNPs in HeLa cells. miR-Lk-number represents small RNA sequences, identified in the miRNP complexes, that cannot be classified as miRNAs under the novel classification code for miRNAs. The sequences are shown $5^{\prime}$ to $3^{\prime}$. The source (Hs; Homo sapiens, Mm; Mus musculus) indicates the species of the cell line from which the RNAs were identified. In this column, - indicates RNAs identified by sequence homology in the human genome. (Chr.); chromosomal localization of the miRNA in the human genome. Dr; Danio rerio, Fr; Fugu rubripes, Dm; Drosophila melanogaster, Ce; Caenorhabditis elegans, Mm; Mus musculus, Rn; Rattus norvegicus. + indicates fully conserved RNAs, and + represents conserved RNAs containing one or two mismatches. 

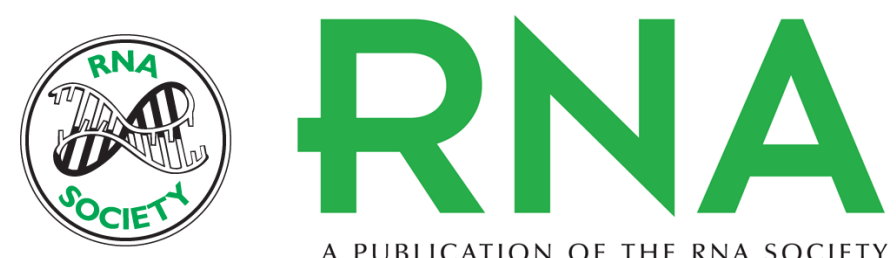

A PUBLICATION OF THE RNA SOCIETY

\section{Numerous microRNPs in neuronal cells containing novel microRNAs}

JOSÉE DOSTIE, ZISSIMOS MOURELATOS, MICHAEL YANG, et al.

RNA 2003 9: 180-186

Related Content Numerous microRNPs in neuronal cells containing novel microRNAs JOSEEE DOSTIE, ZISSIMOS MOURELATOS, MICHAEL YANG, et al. RNA May , 2003 9: 631-632

References This article cites 33 articles, 19 of which can be accessed free at: http://rnajournal.cshlp.org/content/9/2/180.full.html\#ref-list-1

Articles cited in:

http://rnajournal.cshlp.org/content/9/2/180.full.html\#related-urls

License

Email Alerting

Receive free email alerts when new articles cite this article - sign up in the box at the Service top right corner of the article or click here.

To subscribe to RNA go to:

http://rnajournal.cshlp.org/subscriptions 